\title{
EXPLORING THE VALIDITY OF THE PROBLEM SOLVING INVENTORY WITH MEXICAN AMERICAN HIGH SCHOOL STUDENTS
}

\author{
A manuscript presented to the Faculty of the Educational, School \\ and Counseling Psychology Department \\ University of Missouri-Columbia
}

\author{
In Partial Fulfillment \\ of the Requirements for the Degree \\ Master of Arts
}

by

YU-PING HUANG

Dr. Lisa Y. Flores, Manuscript Supervisor April 2005 


\begin{abstract}
The Problem Solving Inventory (PSI; Heppner \& Petersen, 1982) is a widely used measure to assess one's perceived ability in problem-solving behaviors and attitudes in the United States and many other countries. In this study, a bilevel model was examined with a Mexican American high school student sample $(\mathrm{N}=164)$ using confirmatory factor analysis. Results of the confirmatory factor analysis supported the bilevel model with the current sample of Mexican American high school students. The data provided support for the PSI and enhances the generalizability of some of the previous findings based on the U.S., Turkish, and South African samples. Also, this study provides crosscultural information that promotes our knowledge about the efficacy of problem-solving constructs across different age and cultural groups.
\end{abstract}




\section{Acknowledgments}

First and foremost I wish to acknowledge my manuscript advisor, Dr. Lisa Flores, for her unwavering support and help with manuscript. She has been the most influential teacher and mentor I have ever had. Without her, this manuscript would not have been possible. I thank her for her patience and encouragement that carried me on through difficult times, and for her insights and suggestions that helped to shape my research skills. Her valuable feedback contributed greatly to this manuscript.

I also wish to acknowledge Dr. Tiffany Whittaker for giving me valuable input and help related to statistics in the manuscript, Dr. Puncky Heppner for providing information about problem-solving appraisal, and Rachel Navarro for her friendship and assistance. I want to thank all my friends at the University of Missouri-Columbia, for being the warm and supportive family during the past two years.

Finally, I would like to express my sincere gratitude and appreciation to my parents and two sisters in Taiwan for their understanding, support and belief in my quest to study abroad in counseling psychology. I am also grateful to Tien-Yu Change for his unfaltering support. Thank You. 
Exploring the Validity of the Problem Solving Inventory with Mexican American High School Students

The Problem Solving Inventory (PSI) (Heppner, 1988; Heppner \& Petersen, 1982) has been applied to more than 120 studies in the past 20 years (Heppner, Witty, \& Dixon, 2004). Problem-solving appraisal has been linked to a wide rage of psychological variables, including depression (e.g., Dixon, Heppner, Burnett, Anderson, \& Wood, 1993), hopelessness (e.g., Bonner \& Rich, 1992), suicidal ideation (e.g., Bonner \& Rich, 1987), help-seeking (e.g., Neal \& Heppner, 1986), psychological distress (e.g., Heppner \& Anderson, 1985; Nezu, 1985), physical health (e.g., Elliott, 1992), coping behavior (e.g., Heppner, Reeder \& Larson, 1983), career planning and decision making (e.g., Larson \& Heppner, 1985; Heppner \& Krieshok, 1983), and study habits and academic performance (Elliot, Godshall, Shrout, \& Whitty, 1990). In addition, problem-solving appraisal has been linked to a host of behavioral, affective and cognitive activities related to personal problem-solving (Heppner, 1988). These studies demonstrate the important role of the problem-solving appraisal in personal adjustment.

Problem-solving appraisal is relevant for educators, psychologists, and student affairs professionals (Heppner \& Baker, 1997). For example, educators are interested not only in increasing knowledge about some specific topics but also in increasing students' problem-solving abilities. Similarly, student affairs professionals are often interested in psychoeducational programming to improve specific skills (e.g., assertiveness), as well as general problem-solving skills for preventive purpose. Problem-solving is a topic that has a great deal of applicability for practitioners as they work to increase the problem-solving 
effectiveness of a broad range of people (e.g., children, adolescents, college students, adults, and older adults.)

The PSI has demonstrated acceptable internal consistency across independent samples and cultural groups; however, most of the PSI research has been conducted with European American college students (Neville, Heppner, \& Wang, 1997). Thus far, the cross-cultural studies of the PSI have included African American college students (Harrison, 1994; Neville, Heppner, \& Wang, 1997), French-speaking Canadian adults (Marcotte, Alain, \& Gosselin, 1999), Turkish college students (Sahin, Sahin, \& Heppner, 1993), South African college students (Heppner, Pretorius, Wei, Lee, \& Wang, 2002; Pretorius, 1992, 1993, 1996; Pretorius \& Diedricks, 1994), and adolescents in China (Cheng \& Lam, 1997).

Among the samples of primarily White college students, the estimates of internal consistency of each of the factor scores as well as the total PSI score ranged from .72 to .90 (Heppner, 1988; Moss, 1983). The PSI has also been found to have acceptable internal consistency estimates across various cultures (e.g., Heppner et al., 2002; Pretorius, 1993; Sahin et al., 1993). The alpha coefficients ranged from .83 to .89 for the PSI total, .76 to .79 for PSC, .77 to .84 for AAS, and .69 to .72 for PC. The estimates of stability of PSI scores were provided for 2 weeks to 2 years across different samples (Heppner, Witty, \& Dixon, 2004). According to Heppner (1988), the total PSI scores correlated .80 over 2 weeks, .81 over 3 weeks as well as 4 months, and .60 over 2 years with samples of White college students, Black college students, and French Canadian adults. 
There are a wide range of studies that supported the validity of the PSI. As evidence of construct validity, the three factor scores and the total PSI score were related to students' problem-solving self-reports (e.g. Rath, Langenbahn, Simon, Sherr, Fletcher, \& Diller, 2004) and ratings of level of program-solving skills and perceived level of satisfaction with skills (Heppner \& Petersen, 1982). The PSI also predicted a wide range of psychological adjustment factors, such as anxiety, hopelessness, depression, and selfesteem (Heppner \& Baker, 1997). Discriminant validity evidence was provided by Heppner and Petersen (1982), who reported that correlations between the PSI factors and both verbal and quantitative intelligence measures of the SCAT, Series II (Educational Testing Service, 1979) were small: PSC ( $r=.08-.10)$, AAS $(r=.11-.12)$, and PC $(r=.09$ $.15)$, respectively.

Several studies examined the factor structure of the PSI via the exploratory factor analysis or confirmatory factor analysis with samples of Midwestern White college students (e.g. Heppner, Baumgardner, Larson, \& Petty, 1988), French Canadian adults (LaPorte, Sabourin, \& Wright, 1988), South African college students (Heppner et al., 2002), Turkish college students (Sahin et al., 1993), and Midwestern high school students (Heppner, Manley, Perez, \& Dixon, 1994). From the findings of these studies, the PSI factors replicated well across different age and cultural groups.

Although the findings for the groups indicate strong test-retest reliability, a stable factor structure, and associations with psychological health, it seems too early to conclude the PSI's cross-cultural applicability. More research is needed with non-White samples to extend knowledge about problem-solving appraisal in diverse groups as well as extended the external validity of the PSI. According to Lucas (2004), these samples 
may or may not have been representative of their population as a whole. For example, the Chinese sample was collected in Hong Kong where people have unique colonial culture and history which might be different than others in Mainland China or Taiwan.

In his critique of the PSI, Leong (1990) indicated that more attention is needed to examine psychometric issues with people of color. In their recent reactions to a specific discussion of the PSI, researchers simultaneously made the notion of the need for further research on the PSI with respect to diversity issues (i.e., race/ethnicity, age, gender, sexual orientation, and social class) (Suzuki, 2004; O’Neil, 2004; Lucas, 2004). Heppner and his colleagues (2004) suggested that the knowledge base and limitations on the PSI would be significantly extended by examining the generalizability or external validity of the existing PSI literature to other populations.

Among the racial and ethnic groups in the United States, the Mexican American population has grown tremendously within the last decade and continues to grow at a rapid pace. Of particular concern is the educational future of Mexican American youth. Specifically, Latino/as graduate from high school (57\%) and college (11\%) at lower rates than their White, Asian, and Black peers (U.S. Census Bureau, 2000). In addition, Mexican American high school students struggle with substance abuse (Morgan-Lopez, Castro, \& Chassin, 2003; Ramirez, Gallion, \& Espinoza, 1999; Simpson, Joe, \& Barrett, 1991), adolescent pregnancy (Del Rio, 1999), anxiety (Glover, Pumariega, \& Holzer, 1999), and depression (Roberts, Roberts, \& Chen, 1997; Roberts \& Chen, 1995). Thus, it is important to understand the role of problem-solving appraisal on Mexican-American youth as this construct may then be used to understand how they deal with various 
stressors in their lives. Adequate measures of problem-solving appraisal are needed for this group.

The primary purpose of this study is to extend previous research findings by examining the psychometric properties and the factor structure of the PSI with Mexican American high school students. To date, no studies have examined the validity of the PSI with Mexican American samples. Internal consistency reliabilities for the PSI will be presented. In addition, a confirmatory factor analysis will be used to determine if the PSI factor structure with a Mexican American sample is consistent with the factor structure reported in previous studies (Heppner, 1988; Heppner et al., 2002; Sahin et al., 1993). According to Piedmont and Chae (1995), a confirmatory factor analysis is the most appropriate method for an etic approach to evaluate the extent to which an original factor structure can be recovered within another culture. Moreover, the etic approach focuses on the phenomena shared by human beings while incorporating culture-specific knowledge into the understanding of the constructs under study (Carter \& Qureshi, 1995). Furthermore, Heppner et al. (2002) examined the generalizability of problem-solving appraisal in Black South Africans, and their study provides a strong framework for this current study. The authors used the confirmatory factor analysis to test three different models: the one-general-factor model (a general PSI total score), the three-correlatedspecific-factors mode (PSC, AAS, and PC), and the bilevel model (a combination of the general and specific factor model). They found that the bilevel model presented the best fit among South African samples. Therefore, the bilevel model will be examined in the current study. 
Another purpose of the present study was to increase our understanding of problemsolving by comparing problem-solving appraisal scores across different cultures. Specifically, independent group comparisons on PSI scores will be conducted to determine if Mexican American high school students scored differently from samples of primarily White college students (Heppner, 1988), African American college students (Heppner, 1988), Turkish college students (Sahin et al., 1993), and South African college students (Pretorius, 1993).

There are three hypotheses in this study. First, it is hypothesized that the PSI would exhibit adequate internal consistency reliability. Next, the factor structure of the PSI with Mexican American high school student sample would support the use of the three factors of the PSI (i.e., Problem-Solving Confidence, Approach-Avoidance Style, and Personal Control) and a general problem-solving factor (the PSI total score), which is often presented in the PSI literature in the United States (Heppner \& Baker, 1997). Finally, it is hypothesized that PSI scores with the Mexican American high school sample would be comparable to scores reported from samples in previously published studies. Thus, the results are expected to provide support for the assessment of problem-solving appraisal using the PSI for Mexican Americans' in the United States. Other psychometric estimates (i.e., reliability, and factor inter-correlations) will be examined.

\section{Method}

\section{Participants}

The sample consisted of 164 (43\% female; 57\% male) Mexican American students attending two public high schools. The schools enrolled a large percentage of 
Mexican American students and were located in a rural city near the Texas-Mexico border. The majority of the participants were $10^{\text {th }}$ graders $(58 \% ; n=95)$, followed by $11^{\text {th }}$ graders $(23 \% ; n=38), 12^{\text {th }}$ graders $(14 \% ; n=23)$, and $9^{\text {th }}$ graders $(3 \%, n=5)$. Three students $(2 \%)$ did not indicate grade level. Students' age ranged from 14 to 20 years with a mean age of 16.3 years $(\mathrm{SD}=.995)$. Among the participants, $29(18 \%)$ identified as first generation (i.e., student born in Mexico), 60 (36\%) as second generation (i.e., student born in U.S.; one parent born in Mexico), 21(13\%) as third generation (i.e., student born in U.S.; both parents born in U.S.; all grandparents born in Mexico), 32 (19\%) as fourth generation (i.e., student and parents born in U.S.; at least one grandparent born in Mexico), and $16(10 \%)$ as fifth generation. Six students (4\%) did not indicate generation level.

Instruments

Demographic questionnaire. A demographic survey was included to gather information about participants' age, gender, grade level, race, generational status, and career choices.

Problem-Solving Appraisal. The Problem Solving Inventory-Form B (PSI; Heppner, 1988; Heppner \& Petersen, 1982) is a measure of self-perceived problemsolving ability and consists of 35 items (including 3 filler items). Participants responded to items using a 6-point Likert scale ranging from strongly agree (1) to strongly disagree (6). The PSI is comprised of three subscales: Problem-Solving Confidence (PSC; 11 items) measures the level of self-assurance while engaging in problem-solving activities (e.g. "I am usually able to think of creative and effective alternatives to my problems"); Approach-Avoidance Style (AAS; 16 items) measures the tendency to avoid or approach 
various problem-solving activities (e.g. "When I have a problem, I think of as many possible ways to handle it as I can until I can’t come up with any more ideas"); and Personal Control (PC; 5 items) assesses the belief that one is in control of emotions and behaviors while engaged in problem-solving activities (e.g. "When my first efforts to solve a problem fail, I become uneasy about my ability to handle the situation"). Scores for the PSI can be used as a single measure of problem-solving appraisal (sum of all items) or by subscale (sum of items on subscale). Low scores on the PSI indicate greater perception of effective problem-solving ability, an approach problem-solving style, the presence of personal control, and overall problem-solving appraisal.

The PSI has demonstrated acceptable internal consistency among different samples (e.g., substance abusers, college students) and cultural groups (e.g., Black South Africans) with alpha coefficients ranging from .72 to .90 (Heppner, 1988; Heppner et al., 2002). Furthermore, the reliability coefficients for the total inventory and for each factor at 2 weeks were $.89, .85, .88$, and .83 respectively. At 3 weeks they were $.81, .78, .77$, and .81 . The last retesting produced coefficients of .60, .65, .61, and .44 (Heppner, 1988). Validity estimates indicate that the PSI is positively related to subjective career distress, active problem-solving, and academic self-efficacy, $.38, .37$, and .38 , respectively (Larson, Toulouse, Ngumba, Fitzpatrick, Heppner, 1994).

\section{Procedure}

Students were invited to participate in the study and were allowed class time to complete the surveys. Student participants completed the research packet during two consecutive 50-minute classes in their classroom. Parents received an informed consent form prior to the data collection. All students received pencils for participating in the 
study and were entered into a random drawing for T-shirts, caps, and gift certificates to local movie theaters, restaurants and stores.

\section{Results}

\section{Reliability}

Estimates of internal consistency were examined for the PSI total and each of the 3 factors. For the current study (see Table 1), the alpha coefficients were as follows: .86 for PSI total, .77 for PSC, .76 for AAS, .66 for PC.

\section{Preliminary Analyses}

The means, standard deviations, range, skewness, kurtosis, and reliability coefficients, for each of the measured variable in this study are present in Table 1 . The skewness and kurtosis values were examined to determine if the variables met the assumptions of normality (e.g. expected range should be between -1.00 to 1.00 ). The test of multivariate normality demonstrated that the data met these assumptions.

\section{Confirmatory Factor Analysis (CFA)}

To test the first hypothesis that the PSI assesses one general factor as well as three specific factors, the bilevel model was examined via CFA. According to Heppner et al. (2002), a bilevel model was indicated as the best representative model in South African college sample. Specifically, the bilevel model consists of 3 first-order factors (e.g., PSC, AAS, and PC) and the second-order factor is 1 general factor (e.g., PSI). That is, each indicator (e.g. PSI items) loads on both a general factor and 1 of the 3 specific factors of the PSI (see Figure 1). 
Prior to conducting the CFA for the PSI with the sample of Mexican American high school students, we carried out an item bundling (or parceling) procedure. In general, the purpose of item bundling is to (a) estimate fewer parameters for both the individual constructs and the hypothesized model, (b) lessen the impact of statistically unreliable individual items (e.g., items with lower reliabilities and communalities), (c) diminish the possibility that items will load on more than one factor, (d) decrease the chances of correlated residuals, and (e) reduce influence of sampling error, (MacCallum, Widaman, Zhang, \& Hong, 1999). In Heppner et al.'s study (2002), the authors divided the 32 items from the three PSI factors into 9 bundles ( 3 bundles for PSC, 4 bundles for AAS, and 2 bundles for PC). The same factor structure was used in this current study (See Figure 1). Next, on the basis of factor loadings for each factor and assigned items, the items were rank-ordered. The specific procedure presented by Little, Cunningham, Shahar, and Widaman (2002) was used, Item-to-Construct Balance, to create bundles with equivalent item difficulty and discrimination. For example, for the PSC latent variable, items ranked 1, 6, 7, and 11 for the PSC were assigned to Bundle 1 (PSC1), items ranked 2, 5, 8, and 10 to Bundle 2 (PSC2), and items 3, 4, and 9 to Bundle 3 (PSC3). The correlation matrix among the 9 item-bundles of the PSI are presented in Table 2 .

Next, a CFA was conducted to test the original three-factor orthogonal structure of the PSI using the EQS (Version 6.1) statistical package (Bentler \& Wu, 1993). A variety of goodness-of-fit indices were used to assess the adequacy of the model fit, including the chi-square test $\left(\chi^{2}\right.$; Kline, 1998; best if not significant), the chisquare/degrees of freedom ratio ( $\chi^{2} / d f$; Kline, 1998; best if less than 2.0), the comparative 
fit index (CFI; Loehlin, 1998; best if .95 or greater), the goodness-of-fit index (GFI; Loehlin, 1998; best if .95 or greater), the root-mean-square error of approximation (RMSEA; MacCallum, Browne, \& Sugawara, 1996; best if .05 or less), and the standardized root-mean-squared residual (SRMR; Loehlin, 1998; best if .05 or less). See Table 3 for the model-fit statistics. In general, $\chi^{2} / d f$ ratios ranging from 2 to 5 are considered to represent adequate model fit (Tanaka, 1993). Examination of the CFI (.95), GFI (.94), RMSEA (.10), SRMR (.04) indicated that the model was an appropriate fit of the data. In conclusion, these results suggest provide empirical support for a bilevel model for the current sample.

Factor Intercorrelations.

Intercorrelations among the factors are present in Table 1. The correlation among the factor scores were as follows: $\mathrm{PSC} / \mathrm{AAS}=.59, \mathrm{PSC} / \mathrm{PC}=.13, \mathrm{AAS} / \mathrm{PC}=.49$.

\section{Group Comparisons}

Table 4 shows the PSI means and standard deviations for the Mexican American sample. Lower scores indicate that the individual perceives himself/herself as more confident in problem- solving, has a tendency to approach problems, and perceives more personal control over his/her problems. For comparative purposes, PSI means and standard deviations are also presented in Table 4 from previous studies using primarily White American college students and African American college students (Heppner, 1988), Turkish college students (Sahin et al., 1993), and South African college students (Pretorius, 1993). When comparing the current study with those of previously published samples, Bonferroni adjustments were made to significance levels to control for Type II error. Therefore, significance levels were set at $.013(.05 / .4=.013)$. for the PSC, AAS, 
PC, and PSI, respectively. The $t$-test comparisons show that for the total PSI score, White American college men scored lower than Mexican American high school men, and Turkish college women scored lower than Mexican American high school women. For Problem-Solving Confidence, White American college men and women both scored lower than Mexican American high school men and women, respectively. For the Approach-Avoidance factor, Turkish college men and women both scored lower than Mexican high school men and women, respectively. For the Personal Control factor, there were no statistically significant differences between these groups.

To compare the scores of Mexican American male and female the PSI total and its three factors, a between-subjects multivariate analysis of variance (MANOVA) was conducted (see Table 5). The mean and standard deviation by gender are reported in Table 4. The MANOVA revealed no significant gender difference on the PSI total and the three factors, Wilk's Lambda $F(4,159)=1.63, p>.05$.

\section{Discussion}

The purpose of the present research was to examine the validity of problemsolving appraisal with Mexican American high school students via a confirmatory factor analysis and group comparisons to various cultural groups. The results of this study support and extend previous research conducted with samples of primarily White college students (Heppner, 1988), Black college students (Heppner, 1988), South African college students (Pretorius, 1993), and Turkish college students (Sahin et al., 1993). The results from this study indicate that the PSI means, standard deviations, estimates of internal consistency from the Mexican American high school samples are comparable to those 
revealed in previous research studies. The results of this study also suggest that the psychometric properties of problem-solving appraisal as measured by the PSI seem to generalize to Mexican American high school students. Thus, findings suggest that the PSI may be a useful instrument to examine problem-solving appraisal with Mexican American high school students.

These initial estimates of reliability suggest that the PSI and the three factors have acceptable levels of internal consistency with the Mexican American high school sample. Compared to previous studies (Heppner, 1988; Heppner et al., 2002; Pretorius, 1993; Sahin et al., 1993), the PSI demonstrated acceptable internal consistency with the alpha coefficients ranging from .83 to .90 for PSI total, .76 to .84 for PSC, .77 to .84 for AAS, and .69 to .72 for PC. In the current study, the factor, PC showed lower internal consistency (.62) than PSC and AAS, however, this is consistent with the alpha coefficient reported with a sample of high school students (Heppner et al., 1994).

The results of the confirmatory factor analysis indicated that the factor structure of the PSI supported the three factors of the PSI and a general problem-solving factor with Mexican high school student sample. That is consistent with Heppner et al's (2002) study on South African college students. Therefore, this study provides additional support for the generalizability of the PSI factor structure to a Mexican American high school sample. These results suggest considerable consistency of the PSI factor structure across various cultures and to a high school sample, and imply that problem-solving appraisal as measured by the PSI may be a useful construct across different cultures.

The factor intercorrelations ranged from .36 to .69 in the primarily White college sample (Heppner, 1988) and .47 to .53 in South African college sample (Heppner et al, 
2002). In the present study, the correlations between problem-solving confidence and approach/avoidance style (PSC/AAS) and the personal control (AAS/PC) showed similar results, but the correlation between the problem-solving confidence and personal control (PSC/PC) is lower than that reported in previous studies (.13). Results suggest that further examination of the relationship between PSI and PC is needed, especially with Mexican American sample.

An important finding from this study is that Mexican American male high school students perceived lower problem-solving ability and had lower problem-solving confidence than a sample of U.S. White college male students. It is possible that the ethnic cultural background might contribute to these differences. In Latino/Latina culture, one important cultural dimension is allocentrism, which is a form of collectivism (Marin, 1994). Another related value, familismo (familialism), places the needs of the family over individual needs (Falicov, 1998; Santiago-Rivera, Arredondo, \& Gallardo-Cooper, 2002). Due to these cultural values, it is possible that Mexican American high school men may rely more on their family members to problem-solving stressful events. According to Bandura's self-efficacy theory $(1986,1989)$, the most effective way of creating a strong sense of efficacy is through mastery experiences. Thus, Mexican American high school men's reliance on family might contribute to fewer experiences in which they deal with problems independently. In addition to the ethnic cultural background, age difference might also be a crucial factor. Due to the age difference, college men might have more life experiences and more opportunities and improve their problem-solving skills than high school men. For example, college men have more opportunities to expose 
themselves in a more diverse environment, which might help them develop confidence in problem-solving.

South African college men perceived stronger problem-solving ability, higher confidence and personal control, and tended to approach problems instead avoid them when compared to Mexican American high school men in the current study. These similar results were found in Pretourius's study (1993), when the researcher compared the South African college sample with the primarily White college sample (Heppner, 1988). Pretourius (1993) suggested that age differences might be a factor that influences one's problem-solving appraisal because South African college men's age $(m=24.21)$ is higher than White college men $(m=19.5)$ and much higher than Mexican American high school men's age $(m=16.35)$. Therefore, in the present study age difference might also play a role affecting high school men's perceived problem- solving ability.

Interestingly, both Turkish female and male college students and South African femle and male college students tended to approach problems, while Mexican American female and male high school students tended to avoid problems. The finding is consistent with the previous study (Sahin et al., 1993) where Turkish college students attempted to take stronger approach styles than U.S. White college students. Due to the highly competitive examinations in Turkey, with about a 20\% acceptance rate (Sahin et al., 1993), the sample of Turkish college students might be a select group from the whole Turkey society. Therefore, Turkish college students may have more resources and support to solve their problems in a more approaching style.

Additionally, understanding Latino/Latina culture might also help us understand Mexican American youth's problem-solving style. Simpatica which means a preference 
for conflict-free relationships involves avoiding situations where feelings. Thus, it is possible that the reason Mexican American female and male high school students tend to have an avoidance problem-solving style is because they value conflict-free relationships. South African college male and female students also perceived higher on approaching than avoiding problems when compared to Mexican American high school male and female, respectively. The finding is consistent with the previous study as well, where the researcher compared the South African samples with U.S. White college samples (Pretorius, 1993). The South African government controlled every aspect of human life in South Africa through oppressive and discriminatory legislation (Pretorius, 1993). Therefore, it is possible that South Africans develop a more approaching style in dealing with this political situation.

Among the cross-cultural group comparisons, findings also indicated that Turkish college women perceived higher problem-solving appraisal than Mexican American high school women. Other than the age difference, Sahin and his colleagues (1993) pointed out that Turkish women attending college might represent a select group, with a more positive self-image and self-confidence than other Turkish women. Because of this, Turkish women might perceive higher confidence in problem-solving. One of the Latino cultural values is Marianismo, which refers to female gender roles. Mexican American women were socialized to be dependent, submissive, impulsive, docile, gentle, nurturing, and intuitive, especially in the past and in highly traditional families (McNeill, Prieto, Niemann, Pizarro, Bera, \& Gomez, 2001; Santiago-Rivera, Arredondo, \& GallardoCooper, 2002). Therefore, in order to meet their gender role expectations from family, 
Mexican American women might develop lower confidence and perceive more barriers in problem-solving.

In terms of gender differences among Mexican Americans, there have not been statistically significant differences on PSI scores between men and women in the previous studies with American college students, (Heppner, Hibel, Neal, Weinstein, \& Rabinowitz, 1982; Heppner et al., 1983; Larson \& Heppner, 1985; Neal \& Heppner, 1986). However, researchers found that women were more concerned about the future than men (Constantine, Chen, \& Cessay, 1997). Betz (1994) also discussed environmental and individual obstacles experienced especially by women. Even though there is no difference among Mexican American high school men and women in this study, it might be helpful to understand the needs of men and women in problem-solving, respectively.

The present findings also have implications for counseling practice. Because the PSI present not only a general factor but also three specific factors, it might be helpful for school counselors to help high school students become more aware of what factors influence their perceived problem-solving ability. In addition, due to a possible lack of experiences to successfully practice problem-solving skills, Mexican American high school students may perceive more barriers in problem-solving than college students. Therefore, counselors can help Mexican American high school students increase confidence by teaching them some problem-solving skills (e.g. exploring options), providing opportunities to practice their skills, and providing support and encouragement when they accomplish these problem-solving tasks. The other way of creating and strengthening 
self-efficacy is through vicarious experiences provided by role models (Bandura, 1986, 1989). Thus, counselors and family members can be the social models in effective problem-solving for Mexican American high school students.

Mexican Americans are the fastest growing racial groups in the United States. It is important to address the impact of the problem-solving appraisal on their educational and career development as well as their psychological well-being. Researchers found that individuals with higher appraisals of their problem-solving abilities were more confident in their decision-making ability than negatively appraised problem-solvers (Larson \& Heppner, 1985). Therefore, school counselors might also help students gain problemsolving skills in order to assist in their adjustment and educational and career development.

Findings from this study are based on a sample of Mexican American high school students from a rural city near the Texas-Mexico border. In terms of students' background (e.g. grade, generation level, and acculturation), this sample might not represent other Mexican American high school students across the U.S. Therefore, the generalizability of the findings to other Mexican American high school students is not known. More studies are needed to determine if the PSI factor structure exhibits similar findings in other Mexican American high school studies. Next, given the small size of the sample in the present study, more research is needed to examine the factor structure of PSI with larger samples of Mexican American high school students, particularly the bilevel model.

Also, problem-solving appraisal has been investigated in previous studies with the predominantly White college samples, and college students in Turkey and South Africa. 
The only racial ethnic minority group previously examined was a Black undergraduate student sample with small number of participants. Thus, more studies with racial ethnic minority groups in the United States are needed. Furthermore, the current research investigated the validity of PSI with a sample of Mexican American high school students. More studies with Mexican American college students and adults are needed in order to extend the generalizability of findings from this study. Future research might also examine cultural variables that influence Mexican American high school students' problem-solving appraisal, such as acculturation or generation level. Lastly, in the current study and past studies with high school samples (Heppner et al., 1994), personal control has not shown as strong internal consistency when compared to the factors of problemsolving confidence and approach-avoidance style. Researchers might need to further investigate this specific factor in problem-solving with high school students.

Nonetheless, the results of this study provide empirical support for Heppner et al.'s (2002) bilevel model of the PSI with Mexican American high school students. In particular, the three factors of the PSI as well as a general problem-solving factor were presented. These results extend the generalizibility of utilizing the PSI with various cultural groups. The pattern of results in group comparisons indicated that Mexican American high school students perceive more barriers than other cultural groups. The results suggest implications for school counselors. Given the outcome of this study, the Problem Solving Inventory is an appropriate tool for examining problem-solving appraisal with Mexican American high school students. 


\section{Reference}

Betz, N. E. (1994). Basic issues and concepts in career counseling for women. In W.B. Walsh \& S.H. Osipow (Eds.), Career counseling for women (pp. 1-41), Hillsdale, NJ: Lawrence Erlbaum.

Bandura, A. (1986). Social foundations of thought and action: A social cognitive theory. Englewood Cliffs, NJ: Prentice-Hall.

Bandura, A. (1989). Human agency in social cognitive theory. American Psychologist, 44, 1175-1184.

Bentler, P. M., \& Wu, E. J. C. (1993). EQS/Windows User's Guide: Version 4. Los Angeles: BNDP Statistical Software.

Bonner, R. L., \& Rich, A. R. (1987). Toward a predictive model of suicide ideation and behavior: Some preliminary data in college students. Suicide and Life Threatening Behavior, 17, 50-63.

Bonner, R. L., \& Rich, A. R. (1992). Cognitive vulnerability and hopelessness among correctional inmates: A state of mind model. Journal of Offender Rehabilitation, 17, 113-122.

Carter, R. T., \& Qureshi, A. (1995). A typology of philosophical assumptions in multicultural counseling and training. In J. G. Ponterontto, J. M. Casas, L. A. Suzuki, \& C. M. Alexander (Eds.), Handbook of multicultural counseling (pp. 239-262). Thousand Oaks, CA: Sage.

Cheng, S. K., \& Lam, D. J. (1997). Relationships among life stress, problem solving, self-esteem, and dysphoria in Hong Kong adolescents: Test of a model. Journal of Social and Clinical Psychology, 16, 343-355. 
Constantine, M. G., Chen, R. C., \& Cessay, P. (1997). Intake concerns of racial and ethnic minority students at a university counseling center: Implications for developmental programming and outreach. Journal of Multicultural Counseling and Development, 25, 210-218.

Del Rio, S. R. (1999). The influence of acculturation on chicana adolescent pregnancy. (Mexican-Americans, girls). Unpublished doctoral dissertation, California School of Professional Psychology.

Dixon, W. A., Heppner, P. P., Burnett, J. W., Anderson, W. P., \& Wood, P. K. (1993). Distinguishing among the antecedents, concomitants, and consequences of problem solving appraisal and depressive symptoms. Journal of Counseling Psychology, 40, 357-364.

Educational Testing Service (1979). School and college ability tests (SCAT): Series IIII/ Menlo Part, CA: Addison-Wesley.

Elliott, T. R. (1992). Problem-solving appraisal, oral contraceptive use, and menstrual pain. Journal of Applied Social Psychology, 22, 286-297.

Elliott, T. R., Godshall, F., Shrout, J. R., \& Witty, T. E. (1990). Problem-solving appraisal, self-reported study habits, and performance of academically at-risk college students. Journal of Counseling Psychology, 37, 203-207.

Falicov, C. J. (1998). Latino families in therapy: A guide to multicultural practice. New York: Guildford Press.

Glover, S. H., Pumariega, A. J., Holzer, C. E. III (1999). Anxiety symptomattology in Mexican-American adolescents. Journal of Child \& Family Studies, 8, 47-57.

Harrison, H. A. (1994). The relationship among Jungian psychological type preferences, 
problems experienced, and perceived problem-solving capabilities for African Americans holding graduate degrees. Unpublished doctoral dissertation. St. Louis University.

Heppner, P. P. (1988). The Problem Solving Inventory (PSI): Manual. Palo Alto, CA: Consulting Psychologists Press.

Heppner, P. P., \& Anderson, W. P. (1985). On the perceived non-utility of research in counseling. Journal of Counseling and Development, 63, 545-547.

Heppner, P. P., \& Baker, C. E. (1997). Applications of the Problem-Solving Inventory. Measurement and Evaluation in Counseling and Development, 29, 229-241.

Heppner, P. P., Baumgardner, A. H., Larson, L. M., \& Petty, R. E. (1988). The utility of problem solving training that emphasizes self-management principles. Counseling Psychology Quarterly, 1, 129-143.

Heppner, P. P., Hibel, J. H., Neal, G. W., Weinstein, C. L., \& Rabinowitz, F. E. (1982). Personal problem solving: A descriptive study of individual differences. Journal of Counseling Psychology, 29, 580-590.

Heppner, P. P., \& Krieshok, T. S. (1983). An applied investigation of problem-solving appraisal, vocational identity, and career service requests, utilization, and subsequent evaluations. The Vocational Guidance Quarterly, 31, 240-249.

Heppner, P. P., Manley, C. M., Perez, R. M., \& Dixon, W. A. (1994). An adolescent version of the Problem Solving Inventory: Initial reliability and validity estimates. Unpublished manuscript.

Heppner, P. P., \& Petersen, C. H. (1982). The development and implications of a personal problem solving inventory. Journal of Counseling Psychology, 29, 66- 
75.

Heppner, P. P., Pretorius, T. B., Wei, M., Lee, D., \& Wang, Y. (2002). Examining the generalizability of problem-solving appraisal in Black South Africans. Journal of Counseling Psychology, 49, 484-498.

Heppner, P. P., Reeder, B. L., \& Larson, L. M. (1983). Cognitive variables associated with personal problem-solving appraisal: Implications for counseling. Journal of Counseling Psychology, 30, 537-545.

Heppner, P. P., Witty, T. E., \& Dixon, W. A. (2004). Problem-solving appraisal and human adjustment: A review of 20 years of research using the Problem Solving Inventory. The Counseling Psychologist, 32, 344-428.

Kline, R. B. (1998). Principles and practice of structural equation modeling. New York: Guildford Press.

Laporte, L., Sabourin, S., \& Wright, J. (1988). L'inventaire de resolution de problems personels: Une perspective metocognitive. International Journal of Psychology, $23,569-581$.

Larson, L., \& Heppner, P. P. (1985). The relationship of problem-solving appraisal to career decision and indecision. Journal of Vocational Behavior, 26, 55-65.

Larson, L. M., Toulouse, A. L., Ngumba, W. E., Fitzpatrick, L. A., \& Heppner, P. P. (1994). The development and validation of Coping with Career Indecision. Journal of Career Assessment, 2, 91-110.

Little, T. D., Cunningham, W. A., Shahar, G., \& Widaman, K. F. (2002). To parcel or not to parcel: Exploring the question, weighing the merits. Structural Equation Modeling, 9, 151-173. 
Leong, F. T. L. (1990). Problem Solving Inventory. In D. J. Keyser \& R. C. Sweetland (Eds.), Test critiques (Vol. VIII, pp. 574-582). Austin, TX: RPO-ED.

Loehlin, J. C. (1998). Latent variable models: An introduction to factor, path, and structural analysis (3rd Ed.). Mahwah, NJ, US: Lawrence Erlbaum Associate.

Lucas, M. (2004). Problem-solving appraisal in counseling and with different populations. The Counseling Psychologist, 32, 450-459.

MacCallum, R. C., Browne, M. W., Sugawara, H. M. (1996). Power analysis and determination of sample size for covariance structure modeling. Psychological Methods, 1, 130-149.

MacCallum, R. C., Widaman, K. F., Zhang, S., \& Hong, S. (1999). Sample size in factor analysis. Psychological Methods, 4, 84-99.

Marcotte, D., Alain, M., \& Gosselin, M. -J. (1999). Gender differences in adolescent depression: Gender-typed characteristics or problem-solving skills deficits? Sex Roles, 41, 31-48.

Marin, G. (1994). The experience of being a Hispanic in the United States. In W.J. Lonner \& R. Malpass (Eds.), Psychology and culture (pp. 23-27). Boston: Allyn \& Bacon.

McNeill, B. W., Prieto, L. R., Niemann, Y. F., Pizarro, M., Vera, E. M., \& Gomez, S. P. (2001). Current directions in Chicana/o psychology. The Counseling Psychologist, 29, 5-17.

Morgan-Lopez, A. A., Castro, F. G., \& Chassin, L. A mediated moderation model of cigarette use among Mexican American youth. Addictive Behaviors, 28, 583-589.

Moss, S. (1983). Formal \& informal problem-solving and age related differences. 
Unpublished master's thesis, University of Missouri, Columbia.

Neal, G. W., \& Heppner, P. P. (1986). Problem solving self-appraisal, awareness, and utilization of campus helping resources. Journal of Counseling Psychology, 33, 3944.

Neville, H. A., Heppner, P. P., \& Wang, L. (1997). Relations among racial identity attitudes, perceived stressors, and coping styles in African American college students. Journal of Counseling and Development, 75, 303-311.

Nezu, A. M. (1985). Differences in psychological distress between effective and ineffective problem solvers. Journal of Counseling Psychology, 32, 135-138.

O’Neil, J. M. (2004). Response to Heppner, Witty, and Dixon: Inspiring and high-level scholarship that can change people's lives. The Counseling Psychologists, 32, 439449.

Piedmont, R. L., \& Chae, J.-H. (1997). Cross-cultural generalizability of the five-factor model of personality: Development and validation of the NEO PI-R for Koreans. Journal of Cross-Cultural Psychology, 28, 131-155.

Pretorius, T. (1992). Problem-solving appraisal in the association of life stress and depression: A South African study. Psychological Reports, 71, 855-862.

Pretorius, T. (1993). Assessing the problem-solving appraisal of Black South African students. International Journal of Psychology, 28, 861-870.

Pretorius, T. (1996). The family environment of students self-appraisal as effective and ineffective problem. Psychological Reports, 79, 915-921.

Pretorius, T. B., \& Diedricks, M. (1994). Problem-solving appraisal, social support and stress-depression relationship. South African Journal of Psychology, 24, 86-90. 
Ramirez, A. G., Gallion, K. J., Espinoza, R. (1999). Developing a media- and schoolbased program for substance abuse prevention among Hispanic youth: A case of Mirame!/Look at me! Nicotine \& Tobacco Research, 1, 99-104.

Rath, J. F., Langenbahn, D. M., Simon, D., Sherr, R. L., Fletcher, J., \& Diller, L. (2004). The construct of problem solving in higher-level neuropsychological assessment and rehabilitation. Archives of Clinical Neuropsychology, 19, 613-635.

Roberts, R. E., \& Chen, Y.-W. (1995). Depressive symptoms and suicidal ideation among Mexican-origin and Anglo adolescents. Journal of the American Academy of Child \& Adolescent Psychiatry, 34, 81-90.

Roberts, R. E., Roberts, C. R., \& Chen, Y. (1997). Ethnocultural differences in prevalence of adolescent depression. American Journal of Community Psychology, 25, 95-110.

Sahin, N., Sahin, N. H., \& Heppner, P. P. (1993). Psychometric properties of the Problem Solving Inventory (PSI) in a group of Turkish university students. Cognitive Therapy and Research, 17, 379-396.

Santiago-Rivera, A. L., Arredondo, P., \& Gallardo-Cooper, M. (2002). Counseling Latinos and la familia: A practical guide. Multicultural Aspects of Counseling Series, 17, Thousand Oaks, CA: Sage.

Simpson, D. D., \& Barrett, M. E. (1991). A longitudinal study of inhalant use: Overview and discussion of findings. Hispanic Journal of Behavioral Sciences, 13, 341-355.

Suzuki, L. A., \& Ahluwalia, M. K. (2004). Two decades of research on the Problem Solving Inventory: A Call for Empirical Clarity. The Counseling Psychologist, 32, 429-438. 
Tanaka, J. S. (1993). Multifaceted conceptions of fit in structural equation models. In K.A. Bollen and J.S. Long (Eds.), Testing structural equation models (pp. 10-39). Newbury Part, CA: Sage Publications.

U. S. Census Bureau of the Census. (2000). Population Projections of the United States by Age, Sex, and Hispanic Origin: 1999 to 2100 http://www.census.gov/population/www/projections/datdet-D1A.html (accessed on 07 November 2003) 
Table 1

Means, Standard Deviations, Ranges, Reliability Coefficients, Skewness, Kurtosis \& Correlation for the Problem Solving Inventory and its 3 subscales

\begin{tabular}{|c|c|c|c|c|c|c|c|c|}
\hline Variable & $M$ & $\mathrm{SD}$ & Range & $\alpha$ & 1. & 2. & 3. & 4. \\
\hline 1. PSC & 2.58 & .69 & $1.00-4.90$ & .77 & -- & & & \\
\hline 2. AAS & 3.05 & .62 & $1.19-4.19$ & .76 & $.59 * *$ & -- & & \\
\hline 3. $\mathrm{PC}$ & 3.54 & .92 & $1.25-5.80$ & .66 & .13 & $.49 * *$ & -- & \\
\hline 4. PSI & 2.96 & .55 & $1.28-3.90$ & .86 & $.78^{* *}$ & $.93 * *$ & $.59 * *$ & -- \\
\hline Skewness & & & & & .43 & -.76 & -.08 & -.84 \\
\hline Kurtosis & & & & & .61 & .59 & .12 & .29 \\
\hline
\end{tabular}

Note. $\mathrm{PSC}=$ Problem - Solving Confidence $; \mathrm{AAS}=$ Approach-Avoidance Style $; \mathrm{PC}=$ Personal Control $; \mathrm{PSI}=$ Problem Solving Inventory; $\mathrm{N}=164 ; * * \mathrm{p}<.01$ 
Table 2

Correlation Matrix among 9 Item-Bundles of the Problem Solving Inventory (PSI)

\begin{tabular}{|c|c|c|c|c|c|c|c|c|c|}
\hline Item-bundle & PSC1 & PSC2 & PSC3 & AAS1 & AAS2 & AAS3 & AAS4 & PC1 & $\mathrm{PC} 2$ \\
\hline PSC1 & -- & & & & & & & & \\
\hline PSC2 & $.71 * *$ & -- & & & & & & & \\
\hline PSC3 & $.60 * *$ & $.62 * *$ & -- & & & & & & \\
\hline AAS1 & $.33^{* *}$ & $.28 * *$ & $.33 * *$ & -- & & & & & \\
\hline AAS2 & $.49 * *$ & $.35^{* *}$ & $.39 * *$ & $.24 * *$ & -- & & & & \\
\hline AAS3 & $.39 * *$ & $.39 * *$ & $.37 * *$ & $.43 * *$ & $.42 * *$ & -- & & & \\
\hline AAS4 & $.42 * *$ & $.42 * *$ & $.44^{* *}$ & $.56^{* *}$ & $.36^{* *}$ & $.62 * *$ & -- & & \\
\hline $\mathrm{PC} 1$ & $.20 *$ & .04 & -.07 & $.32 * *$ & $.23^{* *}$ & $.29 * *$ & $.28 * *$ & -- & \\
\hline PC2 & $.21 * *$ & .11 & .00 & $.43^{* *}$ & $.18^{* *}$ & $.36 * *$ & $.43^{* *}$ & $.56^{* *}$ & -- \\
\hline
\end{tabular}

Note. PSC1, PSC2, and PSC3 are from 11 items of the Problem-Solving Confidence factor of the PSI; AAS1, AAS2, AAS3, and AAS4 are from 16 items of the Approach-Avoidance Style factor of the PSI; PC1 and PC2 are from 5 items of the Personal Control factor of the PSI. ${ }^{*} p<.05 * * p<$ $.01 ; N=164$. 
Table 3

Summary of Model-Fit Statistics of the Confirmatory Factor Analysis

\begin{tabular}{llllllllll} 
Model & $\chi^{2}$ & df & $p$-value & $\chi^{2} / \mathbf{d f}$ & CFI & GFI & SRMR & RMSEA & $\begin{array}{c}\text { 90\% Confidence Interval } \\
\text { for RMSEA }\end{array}$ \\
\hline $\begin{array}{l}\text { Bilevel } \\
\text { Model }\end{array}$ & 43.87 & 16 & $<.01$ & 2.73 & .95 & .94 & .04 & .10 & $(0.07,0.14)$ \\
\hline
\end{tabular}

Note. $\mathrm{CFI}=$ comparative fit index; GFI = goodness-of-fit index; $\mathrm{SRMR}=$ standardized root mean squared residual; RMSEA $=$ root mean square error of approximation. 
Table 4

Means, Standard Deviations, and Independent Sample t-tests for Mexican American high school students, American college students, and Turkish college students.

\begin{tabular}{|c|c|c|c|c|c|}
\hline Measure and Study & $\begin{array}{c}\text { Sample } \\
\text { Description }\end{array}$ & Mean & $S D$ & $N$ & $t$ \\
\hline \multicolumn{6}{|c|}{ Problem-Solving Confidence } \\
\hline Current study & MA high school men & 28.1 & 7.6 & 71 & \\
\hline Heppner (1988) & White college men & 25.2 & 7.1 & 615 & $3.23^{*}$ \\
\hline Heppner (1988) & Black college men & 24.5 & 8.0 & 25 & 2.01 \\
\hline Sahin et al. (1993) & Turkish college men & 28.8 & 7.0 & 71 & 0.57 \\
\hline Pretorius (1993) & South African college men & 24.0 & 6.2 & 68 & $3.48^{*}$ \\
\hline Current study & MA high school women & 28.1 & 7.6 & 93 & \\
\hline Heppner (1988) & White college women & 26.2 & 7.4 & 836 & 2.34 \\
\hline Heppner (1988) & Black college women & 25.7 & 6.7 & 59 & 2.00 \\
\hline Sahin et al (1993) & Turkish college women & 26.4 & 7.1 & 153 & 1.77 \\
\hline Pretorius (1993) & South African college women & 25.7 & 7.7 & 140 & 2.34 \\
\hline \multicolumn{6}{|c|}{ Approach-Avoidance Style } \\
\hline Current study & MA high school men & 49.1 & 10.1 & 71 & \\
\hline Heppner (1988) & White college men & 46.7 & 9.5 & 615 & 2.00 \\
\hline Heppner (1988) & Black college men & 44.1 & 11.8 & 25 & 2.04 \\
\hline Sahin et al (1993) & Turkish college men & 43.3 & 9.4 & 71 & $3.54^{*}$ \\
\hline Pretorius (1993) & South African college men & 41.8 & 8.8 & 68 & $4.54^{*}$ \\
\hline Current study & MA high school women & 47.6 & 9.6 & 93 & \\
\hline Heppner (1988) & White college women & 45.5 & 10.3 & 836 & 1.88 \\
\hline Heppner (1988) & Black college women & 44.6 & 11.5 & 59 & 1.73 \\
\hline
\end{tabular}


Table 4 (Continued)

Means, Standard Deviations, and Independent Sample t-tests for Mexican American high school students, American college students, and Turkish college students.

\begin{tabular}{|c|c|c|c|c|c|}
\hline Measure and Study & $\begin{array}{c}\text { Sample } \\
\text { Description }\end{array}$ & Mean & $S D$ & $N$ & $t$ \\
\hline \multicolumn{6}{|c|}{ Approach-Avoidance Style } \\
\hline Sahin et al (1993) & Turkish college women & 42.8 & 10.2 & 153 & $3.66^{*}$ \\
\hline Pretorius (1993) & South African college women & 40.5 & 10.4 & 140 & $5.26^{*}$ \\
\hline \multicolumn{6}{|l|}{ Personal Control } \\
\hline Current study & MA high school men & 17.4 & 4.8 & 71 & \\
\hline Heppner (1988) & White college men & 16.5 & 4.5 & 615 & 1.58 \\
\hline Heppner (1988) & Black college men & 15.9 & 5.0 & 25 & 1.33 \\
\hline Sahin et al (1993) & Turkish college men & 16.7 & 3.3 & 71 & 1.01 \\
\hline Pretorius (1993) & South African college men & 15.3 & 4.7 & 68 & $2.60 *$ \\
\hline Current study & MA high school women & 17.5 & 4.8 & 93 & \\
\hline Heppner (1988) & White college women & 18.0 & 4.5 & 836 & 1.01 \\
\hline Heppner (1988) & Black college women & 18.2 & 5.2 & 59 & 1.38 \\
\hline Sahin et al (1993) & Turkish college women & 16.7 & 3.3 & 153 & 1.55 \\
\hline Pretorius (1993) & South African college women & 17.4 & 5.3 & 140 & 0.15 \\
\hline \multicolumn{6}{|l|}{ Total PSI } \\
\hline Current study & MA high school men & 94.7 & 18.4 & 71 & \\
\hline Heppner (1988) & White college men & 88.4 & 17.2 & 615 & $2.90 *$ \\
\hline Heppner (1988) & Black college men & 84.5 & 20.6 & 25 & 2.31 \\
\hline Sahin et al (1993) & Turkish college men & 89.3 & 17.7 & 71 & 1.78 \\
\hline Pretorius (1993) & South African college men & 80.8 & 15.3 & 68 & $4.83 *$ \\
\hline
\end{tabular}


Table 4 (Continued)

Means, Standard Deviations, and Independent Sample t-tests for Mexican American high school students, American college students, and Turkish college students.

\begin{tabular}{|c|c|c|c|c|c|}
\hline Measure and Study & $\begin{array}{c}\text { Sample } \\
\text { Description }\end{array}$ & Mean & $S D$ & $N$ & $t$ \\
\hline \multicolumn{6}{|l|}{ Total PSI } \\
\hline Current study & MA high school women & 93.2 & 17.7 & 93 & \\
\hline Heppner (1988) & White college women & 89.6 & 18.1 & 836 & 1.82 \\
\hline Heppner (1988) & Black college women & 88.8 & 19.1 & 59 & 1.45 \\
\hline Sahin et al (1993) & Turkish college women & 86.2 & 18.7 & 153 & $2.90 *$ \\
\hline Pretorius (1993) & South African college women & 83.8 & 18.5 & 140 & $3.86^{*}$ \\
\hline
\end{tabular}

Note. $p$ values were adjusted using Bonferroni corrections, ${ }^{*} p<.013$ 
Figure 1. The bilevel model that was tested. The rectangles are measured variables, the large ovals are latent constructs, and the small circles are residual variances. Factor loadings are standardized and are significant $(* \mathrm{p}<.05)$, except for the paths designated "nt," which were fixed at 1 . The variance from F1 to F4 was fixed to 1 . PSI = Problem Solving Inventory; PSC $=$ Problem-Solving Confidence; AAS = Approach-Avoidance Style; PC = Personal Control. 


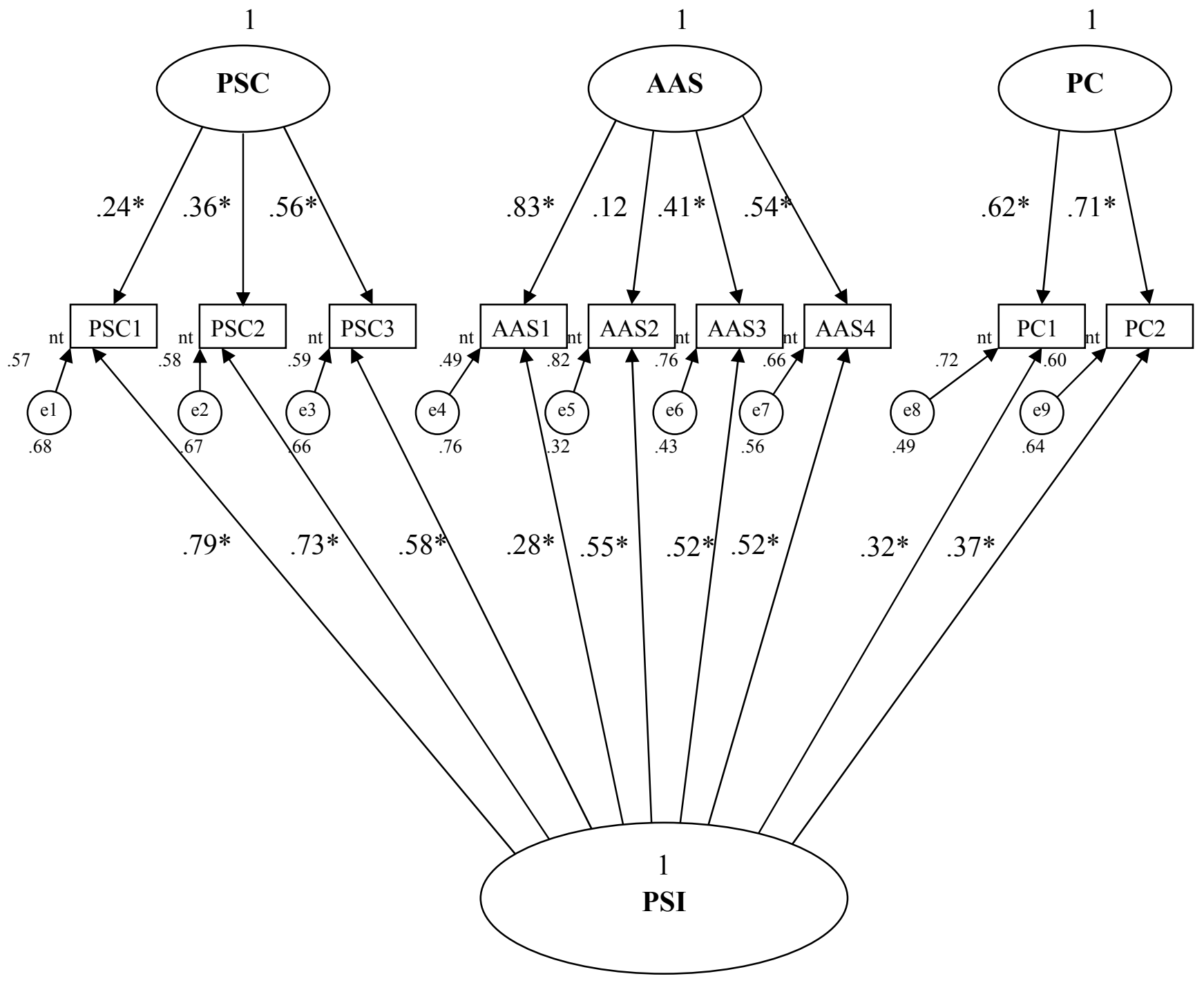


